\title{
RESEARCH ON PRECISION IRRIGATION IN WESTERN SEMIARID AREA OF HEILONGJIANG PROVINCE IN CHINA BASED ON GIS
}

\author{
Q. X. Jiang, Q. Fu*, Z. L. Wang \\ College of Water Conservancy \& Architecture, Northeast Agricultural University, Harbin, \\ 150030, China \\ * Corresponding author, Address: College of Water Conservancy \& Architecture, Northeast \\ Agricultural University, 59 Mucai Road, Harbin, 150030, P. R. China, Tel: +86-451- \\ 55191294, Email: fuqiang@neau.edu.cn
}

Abstract: Geostatistics and GIS were used to analyze the spatial variability of the soil water characteristics in western semiarid area of Heilongjiang province. Irrigation management zone was established based on spatial distribution of the soil water characteristics and actual condition of the study area. Sampling by layered sampling method and calculating of the rational sampling number by best distribution method for each management zone gave the results, saturated water content with the most rational sampling number 15 , whereas natural water content with the least 3 . The rational sampling number determined by layered sampling method was $85 \%-97 \%$ less than the measured sampling number. Measuring the natural water content for each management zone and comparing with the corresponding saturated water content, field moisture capacity and wilting point can determine whether management zone need to be irrigated. In addition, different irrigation lower bounds should be adopted under diverse irrigation requires.

Keywords: GIS, precision irrigation, irrigation management zone, rational sampling number, semiarid area

Jiang, Q.X., Fu, Q. and Wang, Z.L., 2008, in IFIP International Federation for Information Processing, Volume 258; Computer and Computing Technologies in Agriculture, Vol. 1; Daoliang Li; (Boston: Springer), pp. 359-370. 


\section{INTRODUCTION}

For the sake of decreasing resource waste, relieving environmental pollution, enhancing land utility efficiency and reducing agricultural production cost, American agriculturists brought forward the concept of precision agriculture (PA) in the 1990s (Peng et al., 2001). PA is based on $3 \mathrm{~S}$ technique. According to the spatial variability of soil characters, water and fertility status, environmental background and climate condition among crop growing, an integrated series of modern farming operation and management are actualized quantificationally, locationally and timely. PA is also explained as "farming by inch". Different farming modes are taken for diverse soil types in the interest of getting the highest income with the least or the most saving devotion, protecting and improving environment, utilizing various agricultural resources efficiently and obtaining economical and environmental benefit (Cheng, 2004).

PA includes precision fertilization and precision irrigation. PA was started at the research of precision fertilization techniques abroad. Because soil fertility affects crop yield directly, and the technique combing with modern variable rate fertilizer can both decrease funds investment and get high crop yield, scholars in China and abroad put much vigor on it (Shiel et al., 1997; Wang et al., 2004; Hou et al., 2003; Wu et al., 2004). Soil moisture content, water demand status of diverse crops in different periods and variable irrigation technique are all needed for precision irrigation, so it is hard to be actualized. Few papers about precision irrigation are published, and it is just underway in China (Tian et al., 2002). Liu D. J. et al., expatiated on the research significance and prospect of precision irrigation in China (Liu \& Feng, 2006). Liu G. S. utilized GPS water saving irrigation to research precision irrigation (Liu, 2000). Sun L. et al., used automatic drip irrigation system under plastic film on cotton farming to irrigate cotton precisely in its total growth periods, and provided hardware support for precision irrigation (Sun et al., 2004). Hu L. studied on real-time irrigation prediction model of the irrigation distinct and provided accurate prediction model for precision irrigation $(\mathrm{Hu}, 2004)$. Most scholars in China put attention on the research of precision irrigation system and device, and less on irrigation management zone and the quantification of irrigation water. Geostatistics, GIS and sampling technology were used to study the spatial variability of soil water characteristics in western semiarid area of Heilongjiang province in China, and delineate management zone. The implementation scheme was decided by the measurement of natural water content in each management zone. 


\section{MATERIALS AND METHODS}

\subsection{Study Area}

The study was conducted on a 1 ha dry farmland of the dry farming science-technology demonstration park of Chahayang Farm locating at Gannan County in western area of Heilongjiang province, China. The area belongs to cold-temperature continent monsoon climate and semiarid agriculture climate region. The study area was divided by a $10 \mathrm{~m} \times 10 \mathrm{~m}$ grids. One hundred sample points were sampled in the central point of each grid. At each point, three samples were got in diverse depths of the crop growing area extending $30 \mathrm{~cm}$ from the surface. Soil water characteristics were measured and their mean values were considered as the value of each sample point. The experiment was conducted on Sep. 25 in 2006 after harvesting crops and before fall plowing. Sample location was decided by GPS device and basic measurement tools.

\subsection{Measured Items and Methods}

Measured items included natural water content, field moisture capacity, saturation moisture content, wilting point and soil dry bulk density. Soil texture is nearly associated with soil water characteristics, so soil dry bulk density is one of measured items. Drying method was used to measure natural water content, Wilcox method to field moisture capacity, ring knife method to SMC and soil dry bulk density and maximum hygroscopicity method to wilting point.

\section{$2.3 \quad$ Research Methods}

\subsubsection{Geostatistics}

In 1970s, geostatistics was introduced in the field of soil science to overcome the deficiencies of classical Fisher statistics theory in researching the spatial variability of soil characters. The concepts of regionalized variable, random function and stationarity hypothesis are the basis of geostatistics; semi-variance function is its main tool and Kriging interpolation is its means. It is the science used to study nature phenomena which having both randomicity and structure or spatial relativity and dependence (Hou \& Yin, 1998). Using semi-variance function and Kriging interpolation can ascertain the variant degree and spatial relative scale and 
predict the spatial distribution of soil characters to guide precision irrigation and fertilization. Presently using the theory and method of geostatistics to study soil spatial variability quantitatively is the main trend in China and abroad.

\subsubsection{S Technology}

Precision irrigation based on 3S technology utilizes the macroscopical control of RS, the collection, memory, analysis and output of GIS to the data in field and the ground precise measurement of GPS. Then cooperating with the transform of ground information and time control system, according to soil moisture and water demand of diverse crops in different growing period, precision irrigation is actualized timely and properly. GIS with its powerful function is dominant in precision irrigation.

ArcGIS produced by ESRI has perfect function including data input, compilation, query and cartography and powerful ability of second development. It is the most representative product in GIS field recently (Tang \& Yang, 2006). ArcGIS has mighty spatial analysis function which combined GIS and geostatistics perfectly through the module Geostatistics Analyst providing software system for spatial variability research. In ArcGIS, user can import the geographic coordinates and attribute values and utilize Geostatistics Analyst module to get semi-variance function model of regionalized variable and various spatial interpolation figures. ArcGIS also has the functions of zoning, cutting and splicing for the spatial distribution of regionalized variable; powerful calculation function. User can get the results both in figure and data form ( $\mathrm{Li}, 2006)$.

\subsubsection{Sampling Technology}

In a certain acceptance of sampling error, different sampling techniques would be adopted for diverse samples and requires reflecting the general features in the most degree with the least sample number. Simple random sampling and layered sampling are the usual sampling techniques. Random sampling is brief and intuitionistic, but inefficient to estimate population. Layered sampling has high estimating precision and can compute the index of population and layers simultaneously, different layer with diverse sampling method. So layered sampling is used in the study to make sampling survey on soil characteristics (Jin, 2002). Samples quantity is decided by the optimal distribution method one method of layered sampling, and the formula is as follows. 
Population sample size:

$$
n=\frac{\left(\sum W_{h} S_{h}\right)^{2}}{V+\frac{\sum W_{h} S_{h}^{2}}{N}}
$$

Distribution between layers:

$$
n_{h}=\frac{N_{h} S_{h}}{\sum_{h=1}^{L} N_{h} S_{h}} \times n
$$

where, $W_{h}=\frac{N_{h}}{N}$ and $V=\left(\frac{d}{t}\right)^{2}=\left(\frac{r \bar{Y}}{t}\right)^{2}, W_{h}$ is the weight of $h$ layer, $N_{h}$ is the sample number of $h$ layer, $N$ is the sample number of the population, $S_{h}$ is the standard deviation of $h$ layer, $V$ is the variance decided by sample estimation, $d$ is absolute error, $r$ is relative error, $\bar{Y}$ is the mean value of the population, $t$ is the double side $\alpha$ fractile of standard normal distribution, while $p=95 \%$ and $N=100, t=1.984$.

\section{RESULTS AND DISCUSSION}

\subsection{Classical Statistics Analysis of Soil Water Characteristics}

The statistic analysis software SPSS 11.5 was used to analyze the soil water characteristics and the results was shown in Table 1.

Table 1. Classical statistic analysis and normality test of soil water characteristics

\begin{tabular}{lrrrrrrrr}
\hline SWC $^{\mathrm{a})}$ & Mean & \multicolumn{1}{c}{ Max } & \multicolumn{1}{c}{ Min } & $\mathrm{SD}^{\mathrm{b})}$ & $\mathrm{CS}^{\mathrm{c})}$ & $\mathrm{CK}^{\mathrm{d})}$ & $\mathrm{CV}^{\mathrm{e})}(\%)$ & $\mathrm{TD}^{\mathrm{f})}$ \\
\hline NWC $(\%)$ & 19.16 & 22.61 & 15.79 & 1.499 & -0.06 & -0.66 & 7.82 & Normal \\
FMC (\%) & 29.77 & 33.12 & 25.91 & 1.632 & -0.09 & -0.31 & 5.48 & Normal \\
SMC (\%) & 43.91 & 53.79 & 32.24 & 4.933 & -0.13 & -0.69 & 11.24 & Normal \\
WP $(\%)$ & 12.59 & 13.92 & 11.33 & 0.625 & 0.26 & -0.52 & 4.96 & Normal \\
SDBD $\left(\mathrm{g} / \mathrm{cm}^{3}\right)$ & 1.25 & 1.45 & 1.10 & 0.074 & 0.22 & -0.57 & 5.92 & Normal \\
\hline
\end{tabular}

${ }^{a}$ SWC: soil water characteristics; NWC: natural water content; FMC: field moisture capacity; SMC: saturation moisture content; WP: wilting point; SDBD: soil dry bulk density;

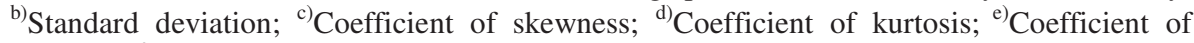
variation; ${ }^{\mathrm{f})}$ Type of distribution.

As shown in Table 1, the mean value of soil moisture had an array as saturation moisture content $>$ field moisture capacity $>$ natural water content $>$ wilting point. The natural water content at that time was between field 
moisture capacity and wilting point. Saturation moisture content had the biggest SD (4.933), whereas soil dry bulk density had the least (0.074), and that of natural water content and field moisture content were close. The CV of saturation moisture content was larger than $10 \%$ belonging to medium variability $(10 \%-100 \%)$, and the others all belonged to small variability $(0-10 \%)$. Before the data were analyzed by geostatistics, normality test should be run on them. For the sample size was big, skewness-kurtosis joint test method was used in the study to test data normality (Shi \& Li, 2006). According to calculating results, random variable belonged to normal distribution when CS and CK less than 0.48 and 0.94 respectively. Under the test and criterion, all soil water characteristics belonged to normal distribution.

\subsection{Semi-variogram Analysis of Soil Water Characteristics}

Semi-variogram is implemental function to research spatial variability in geostatistics. It is utilized to represent the spatial variability structure or spatial continuity of random variable. Semi-variogram was calculated and its model was fitted by the geostatistics software GS+. In GS+, the maximal lag and lag distance should be selected appropriately. When lag exceeds a certain distance, the quantity of sampling point pairs will decrease which leads to increase the randomicity of semi-variogram calculating value, play down the precision of model fitting and even possibly distort the regularity of variability, so the maximal lag is commonly half of the maximal sampling distance (Liu \& Shi, 2003; Cambardella et al., 1994). The maximal lag was $64 \mathrm{~m}$ and lag distance was $10 \mathrm{~m}$ in the study, for the maximal sampling distance was $128 \mathrm{~m}$ and the minimal distance of sampling by grid was $10 \mathrm{~m}$. According to the results form GS+, semi-variogram values of soil water characteristics expressed the same quality on every orientation under $64 \mathrm{~m}$, therefore they were calculated in term of isotropy. After the semi-variogram was calculated, the model was selected and the parameters were adjusted, the model parameters of semi-variogram of soil water characteristics and their fractal dimensions were shown in Table 2.

Table 2. Semi-variance function model and fractal dimension of soil water characteristics

\begin{tabular}{llcccccc}
\hline SWC & $\begin{array}{l}\text { Theoretical } \\
\text { model }\end{array}$ & $\begin{array}{c}\text { Nugget } \\
\mathrm{C}_{0}\end{array}$ & $\begin{array}{c}\text { Sill } \\
\mathrm{C}_{0}+\mathrm{C}\end{array}$ & $\begin{array}{c}\mathrm{C}_{0} /\left(\mathrm{C}_{0}+\mathrm{C}\right) \\
(\%)\end{array}$ & $\begin{array}{c}\text { Range } \\
(\mathrm{m})\end{array}$ & $\mathrm{R}^{2}$ & $\mathrm{FD}^{\mathrm{a})}$ \\
\hline NWC $(\%)$ & Exponential & 0.68 & 2.30 & 29.52 & 30.3 & 0.967 & 1.919 \\
FMC $(\%)$ & Spherical & 0.57 & 2.63 & 21.49 & 23.4 & 0.938 & 1.919 \\
SMC $(\%)$ & Spherical & 4.80 & 23.19 & 20.70 & 19.1 & 0.678 & 1.964 \\
WP $(\%)$ & Spherical & 0.11 & 0.53 & 20.64 & 94.2 & 0.934 & 1.742 \\
SDBD $\left(\mathrm{g} / \mathrm{cm}^{3}\right)$ & Spherical & 0.001 & 0.005 & 22.92 & 19.2 & 0.829 & 1.958 \\
\hline
\end{tabular}

${ }^{a)}$ Fractal dimension 
The theoretical semi-variogram model of natural water content was exponential model, and the others all were spherical models. The fitting precisions $\left(\mathrm{R}^{2}\right)$ of all models were high. According to the comparison among the ratios of nugget and sill $\left(\mathrm{C}_{0} /\left(\mathrm{C}_{0}+\mathrm{C}\right)\right)$, the variant degree of soil water characteristics can be met. The ratio of nugget and sill of natural water content was $29.52 \%$ belonging to medium variability $(25 \%-75 \%)$, and the others belonged to low variability $(0-25 \%)$. There were differences between $\mathrm{CV}$ and the ratio of nugget and sill to partition variability, because $\mathrm{CV}$ was relative to mean value, it represented the variant degree of random variable to mean value; whereas the ratio of nugget and sill represented the variability among variables. And rather the proportion of random and structural factors affecting system total variability could be described via the ratio of nugget and sill. Compared with $\mathrm{CV}$, it could represent the variant degree of regionalized variable and its affecting factors more directly. The ranges (relative distance) of soil water characteristics were greatly different. Wilting point had the longest range $(94.2 \mathrm{~m})$, whereas saturation moisture content had the shortest $(19.1 \mathrm{~m})$. The result implied that sampling distance $(10 \mathrm{~m})$ in the study could satisfy the estimating need of the soil water spatial variability.

\subsection{Ascertainment of Irrigation Management Zone and Reasonable Sampling Number}

As the parameters of theoretical semi-variogram model in Table 2 were imported into the Geostatistical Analyst module, the spatial distributions of soil water characteristics were delineated by ordinary Kriging interpolation and shown in Figure $1(\mathrm{a}-\mathrm{e})$. Field moisture capacity, saturation moisture content and soil dry bulk density had the similar distribution representing banding, and strong negative-correlation existed between soil dry bulk density and field moisture capacity, saturation moisture content respectively. The area that had small soil dry bulk density had large field moisture capacity and saturation moisture content. The coefficients of soil dry bulk density and field moisture capacity, saturation moisture content were -0.98 and -0.85 respectively, which was significant correlation. The distributions of natural water content and wilting point all represented patch.

The tenet of precision irrigation was actualizing different irrigating schemes according to diverse soil moisture. For field moisture capacity, saturation moisture content and wilting point were the important index of deciding irrigation quantity and time, they were main soil water characteristics for delineating irrigation management zone. In addition, the similarity of the spatial distribution and convenient field management were the principle for partition. For the banding distribution of field moisture capacity and saturation moisture content and north-south ridges in study field, the study area was divided into four rectangle subareas (Figure 1(f)). 
From the superposition of the spatial distributions and management zone in Figure $1(\mathrm{a}-\mathrm{e})$, it could be known that the soil water characteristics in each subarea were homogenous and large difference existed among management zones. It accorded with the principles of partition.

The tenet of precision irrigation was actualizing different irrigating schemes according to diverse soil moisture. For field moisture capacity, saturation moisture content and wilting point were the important index of deciding irrigation quantity and time, they were main soil water characteristics for delineating irrigation management zone. In addition, the
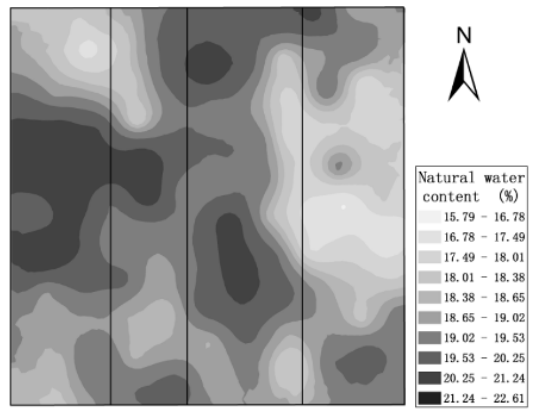

a
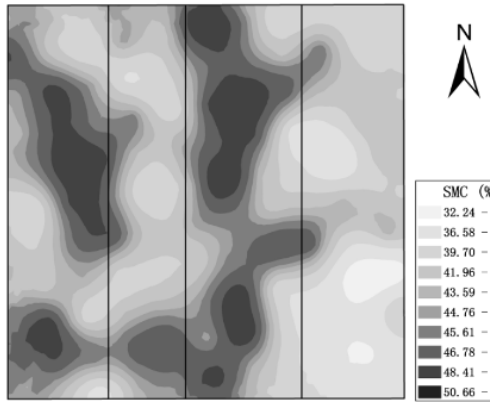

c

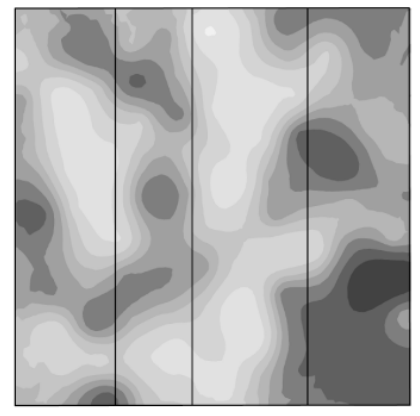

e

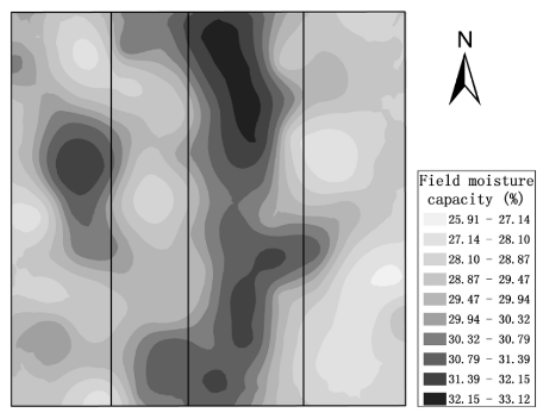

b
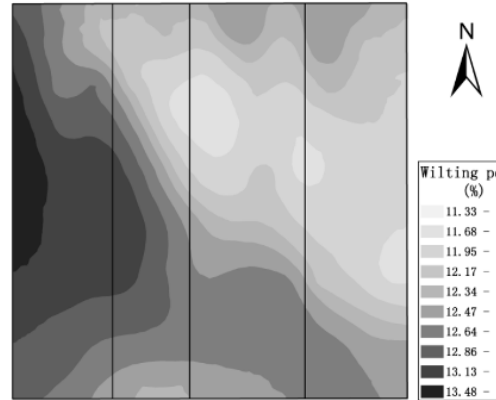

Wilting point

11. $33-11.68$ $11.68-11.95$
$11.95-12.17$ $12.17-12.34$
-11.34 - $12.34-12.47$

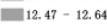
$12.64-12.86$ -12. $86-13.13$ $\begin{array}{r}13.48-13.92 \\ \hline\end{array}$

d

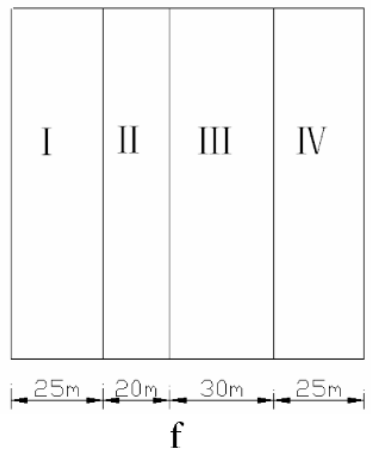

Figure 1. Distribution of soil water characteristics (a-e) and management zone (f) 
similarity of the spatial distribution and convenient field management were the principle for partition. For the banding distribution of field moisture capacity and saturation moisture content and north-south ridges in study field, the study area was divided into four rectangle subareas (Figure 1(f)). From the superposition of the spatial distributions and management zone in Figure $1(\mathrm{a}-\mathrm{e})$, it could be known that the soil water characteristics in each subarea were homogenous and large difference existed among management zones. It accorded with the principles of partition.

After partition for the study area, the statistical eigenvalues of soil water characteristics in each subarea shown in Table 3 had certain differences. The results indicated that diversity existed among eigenvalues of each subarea. The SD and CV of wilting point in the IV subarea compared with that of total area had been reduced by $31.68 \%$ and $29.35 \%$ respectively, simultaneously that of other subareas had been reduced by diverse degree. So the two eigenvalues should be considered for the ascertainment of reasonable sampling number.

After the optimal distribution method was used to calculate the reasonable number for each subarea, at the confidence level of $95 \%$ and the relative allowable error of 5\%, the distributing results of the reasonable sampling number in each subarea were shown in Table 3.

Table 3. Statistical eigenvalue and reasonable sampling number of soil water characteristics for each management zone

\begin{tabular}{|c|c|c|c|c|c|c|c|}
\hline Subarea & $\begin{array}{c}\text { Sampling } \\
\text { number }\end{array}$ & $\mathrm{SE}^{\mathrm{a})}$ & $\begin{array}{c}\text { NWC } \\
(\%)\end{array}$ & $\begin{array}{c}\text { FMC } \\
(\%)\end{array}$ & $\begin{array}{c}\text { SMC } \\
(\%)\end{array}$ & $\begin{array}{l}\text { WP } \\
(\%)\end{array}$ & $\begin{array}{l}\text { SDBD } \\
\left(\mathrm{g} / \mathrm{cm}^{3}\right)\end{array}$ \\
\hline \multirow{4}{*}{ I } & \multirow{4}{*}{25} & Mean & 19.59 & 29.59 & 45.24 & 13.19 & 1.24 \\
\hline & & SD & 1.51 & 1.71 & 4.77 & 0.55 & 0.08 \\
\hline & & $\mathrm{CV}$ & 7.69 & 5.78 & 10.54 & 4.14 & 6.06 \\
\hline & & RSN & 2 & 1 & 4 & 1 & 1 \\
\hline \multirow{4}{*}{ II } & \multirow{4}{*}{20} & Mean & 19.17 & 29.83 & 43.44 & 12.57 & 1.25 \\
\hline & & SD & 1.35 & 1.17 & 3.92 & 0.56 & 0.06 \\
\hline & & $\mathrm{CV}$ & 7.07 & 3.92 & 9.03 & 4.43 & 4.88 \\
\hline & & RSN & 2 & 1 & 3 & 0 & 1 \\
\hline \multirow{4}{*}{ III } & \multirow{4}{*}{30} & Mean & 19.40 & 30.78 & 45.87 & 12.44 & 1.22 \\
\hline & & SD & 1.34 & 1.52 & 4.74 & 0.50 & 0.07 \\
\hline & & $\mathrm{CV}$ & 6.92 & 4.95 & 10.33 & 4.00 & 5.66 \\
\hline & & RSN & 2 & 1 & 4 & 1 & 2 \\
\hline \multirow{4}{*}{ IV } & \multirow{4}{*}{25} & Mean & 18.43 & 28.68 & 40.60 & 12.17 & 1.29 \\
\hline & & SD & 1.59 & 1.27 & 4.49 & 0.43 & 0.07 \\
\hline & & $\mathrm{CV}$ & 8.64 & 4.41 & 11.06 & 3.51 & 5.37 \\
\hline & & RSN & 2 & 1 & 4 & 1 & 1 \\
\hline \multirow{4}{*}{ Total area } & \multirow{4}{*}{100} & Mean & 19.16 & 29.77 & 43.91 & 12.59 & 1.25 \\
\hline & & SD & 1.50 & 1.63 & 4.93 & 0.62 & 0.07 \\
\hline & & $\mathrm{CV}$ & 7.82 & 5.48 & 11.24 & 4.96 & 5.92 \\
\hline & & $\mathrm{RSN}$ & 8 & 4 & 15 & 3 & 5 \\
\hline
\end{tabular}

${ }^{a}$ SE: statistical eigenvalue; RSN: reasonable sampling number 
Among the reasonable numbers of each soil water characteristic, saturation moisture content had the most (15) in total area for its biggest SD, whereas wilting point had the least (3). Natural water content had 2 reasonable sampling points in each subarea. The reasonable sampling number decided by layered sampling method was $85 \%-97 \%$ less than that of actual sampling, which greatly retrenched human and material resources for sampling and decreased the investment of precision irrigation.

\subsection{Actualization of Precision Irrigation}

The spatial distributions of soil water characteristics were transformed into grid figures with the resolution of $0.33 \mathrm{~m} \times 0.33 \mathrm{~m}$ by ArcGIS. Then the spatial distributions were cut by management zone to get the grid figures of each subarea. The mean values of soil water characteristics in each subarea were inquired in the attribute table of grids and were shown in Table 4.

Table 4. Mean value of soil water characteristics for each management zone

\begin{tabular}{lccccc}
\hline SWC & I & II & III & IV & MTA $^{\text {a) }}$ \\
\hline NWC (\%) & 19.45 & 19.27 & 19.32 & 18.46 & 19.12 \\
FMC (\%) & 29.64 & 29.80 & 30.74 & 28.67 & 29.74 \\
SMC (\%) & 45.33 & 43.50 & 45.78 & 40.52 & 43.88 \\
WP (\%) & 13.12 & 12.64 & 12.38 & 12.28 & 12.59 \\
SDBD $\left(\mathrm{g} / \mathrm{cm}^{3}\right)$ & 1.238 & 1.248 & 1.216 & 1.292 & 1.248 \\
\hline
\end{tabular}

${ }^{\mathrm{a})}$ Mean of total area

For greatly affected by climate, natural water content had high variability in time, and so the mean values calculated in the study just represented the status at the sampling time. The other characteristics were considered as non-variability in time, because they were all relative to soil parent material and particle composition. Therefore, natural water content was the only item requiring to be measured while processing precision irrigation.

In the process of precision irrigation, natural water content needed to be known timely and moisture monitoring devices should be buried in the field to get the data. The quantity of the device was the reasonable sampling number of natural water content in each subarea and the distance between them should be larger than its maximum relative distance (range) $30.3 \mathrm{~m}$. The mean value of the natural water content at the two point in each subarea was compared with the mean value of field moisture capacity, wilting point and saturation moisture content in the same subarea to determine whether it need to be irrigated. When the natural water content was between saturation moisture content and field moisture capacity, irrigation was not required. However, when it was less than field moisture capacity and close to wilting 
point, irrigation was needed. Field moisture content was the upper limit of irrigation. While water was ample, $70 \%$ of field moisture content was the lower limit. If water saving irrigation techniques were utilized, the lower limit of irrigation should be ascertained according to the requirements of diverse crops and the water saving irrigation experiments of main crops in the study area. Usually, the lower limit of irrigation should be the lower limit value of the feasible moisture content of the main crops in different stages (Hu, 2004).

\section{CONCLUSIONS}

As the maximum lag by $64 \mathrm{~m}$ and the lag distance by $10 \mathrm{~m}$, the range of wilting point is the longest by $94.2 \mathrm{~m}$ and that of saturation moisture content is the shortest by $19.1 \mathrm{~m}$. Field moisture capacity, saturation moisture content and soil dry bulk density have the similar distribution representing banding. Furthermore field moisture capacity and saturation moisture content have strong negative-correlation with soil dry bulk density respectively. The distributions of natural water content and wilting point all represent patch.

For the banding distribution of field moisture capacity and saturation moisture content and north-south ridges in study field, the study area is divided into four rectangle subareas. In all the subareas, the soil water characteristics in each subarea are homogenous and large differences exist among management zones. It accords with the principles of partition.

After the reasonable sampling number of soil water characteristics are calculated by the optimal distribution method of layered sampling method, saturation moisture content has the most sampling number (15), whereas wilting point has the least (3). The reasonable sampling number decided by layered sampling method is $85 \%-97 \%$ less than that of actual sampling, which will greatly retrench human and material resources for sampling and decrease the investment of precision irrigation.

As the natural water content of each subarea is measured, it will be compared with field moisture capacity, wilting point and saturation moisture content in the same subarea to determine whether it needs to be irrigated. When the natural water content is between saturation moisture content and field moisture capacity, irrigation will not be required. However, when it is less than field moisture capacity and close to wilting point, irrigation is needed. Customarily, field moisture capacity is the upper limit of irrigation and $70 \%$ of it is the lower limit. When water saving irrigation technologies are adopted, the lower limit of irrigation will be the lower limit value of the feasible moisture of the main crops in different stages. 


\section{ACKNOWLEDGEMENTS}

The project is supported by Program for Innovative Research Team of Northeast Agricultural University, "IRTNEAU"; Science \& Technology Tackle Key Problem Program of Heilongjiang (No. GB06B106-7)

\section{REFERENCES}

Cambardella CA, Moorman AT, Novak JM 1994. Field-scale variability of soil properties in central Iowa soils. Soil Science Society of America Journal 58: 1501-1511.

Cheng JC 2004. Technology and application of precision agriculture. Beijing, China, Science Press.

Hou JR, Yin ZN 1998. Practical geostatistics. Beijing, China, Geology Press.

Hou SY, Wang X, Xue XZ 2003. Development of GIS application system for variable rate fertilization in soil precise management. Journal of Hebei University (Natural Science Edition) 23(2): 193-197.

$\mathrm{Hu} \mathrm{L}$ 2004. Real-time forecast model of irrigation in irrigation districts. Nanjing, China, HeHai University.

Jin YJ, Jiang Y, Li XY 2002. Sampling technology. Beijing, China, Renmin Press. pp. 48-51.

Li RX 2006. Coal thickness spatial variability analysis based on geostatistics module in ArcGIS. Energy Technology and Management 1: 97-99.

Liu DJ, Feng JX 2006. Precision irrigation and its prospect analysis. Water Saving Irrigation 43(2): 43-44.

Liu FC, Shi XZ 2003. Characteristics of spatial variability of soil granules in a typical area of southern Jiangsu province. Chinese Journal of Soil Science 34(4): 246-249.

Liu GS 2000. Research on the GPS water-saving irrigation system. Transactions of the Chinese Society of Agricultural Engineering 16(2): 24-27.

Peng WL, Pierre Robert, Cheng HX 2001. Development of agricultural information technology and precision agriculture. Transactions of the Chinese Society of Agricultural Engineering 17(2): 9-11.

Shi Z, Li Y 2006. Geostatistics and its application in soil science. Beijing, China, China Agriculture Press. pp. 21-22.

Shiel RS, Mohamed SB, Evans E 1997. Planning phosphorus and potassium fertilization of field with varying nutrient content and yield potential. In: Stafford JV. ed. Precision agriculture 97. Processings of the First European Conference on Precision Agriculture. Oxford, UK, Bios Scientific Publication Ltd. pp. 171-178.

Sun L, Wang J, Chen X 2004. Experiment demonstration research on precision irrigation index system of cotton in Xinjiang. China Cotton 31(9): 22-24.

Tang GA, Yang X 2006. Experiment tutorial of geographic information system spatial analysis in ArcGIS. Beijing, China, Science Press.

Tian JC, Han BF, Wang BL 2002. Research on precision irrigation. Journal of Ningxia Agricultural College 23(2): 33-36.

Wang X, Zhao CJ, Meng ZJ 2004. Design and experiment of variable rate fertilizer applicator. Transactions of the Chinese Society of Agricultural Engineering 20(5): 114-117.

Wu CC, Ma CL 2004. Research on reasonable distances of soil sampling and fertilizing based on GIS in precision agriculture. Transactions of the Chinese Society for Agricultural Machinery 35(2): 80-83. 